\title{
El derecho griego
}

\author{
Félix Alonso y Royano*
}

\section{GENERALIDADES}

Como dicen Finley, Winton y Garnsey ${ }^{1}$ «toda sociedad de alguna complejidad necesita un aparato que establezca leyes y las haga cumplir, que disponga los servicios comunitarios, militares y civiles y que resuelva las polémicas". Por eso lo que en Occidente hemos dado en llamar Grecia no podía evadirse a este singular principio enunciado por tan eminentes investigadores.

Dícese que Solón de Atenas fue el encargado de codificar las normas por las que habrían de guiarse los diversos grupos en litigios y dada la importancia de la cualidad civil de la vida pública, una serie de instituciones fueron la base en la que habría de sustentarse el derecho en la más arcaica época: Los altares para los sacrificios previos, los oráculos y el juramento. Más tarde en el período clásico estas instituciones irán perdiendo la importancia que tuvieron. Un ejemplo es la evolución del juramento desde la época de Homero ${ }^{2}$ que llevaba toda la carga de una prueba formal hasta la época clásica, aunque no en la helenística, donde el juramento era una simple ceremonia, puesto que para convencer a los jueces y tribunales hacía falta otro tipo de acreditacion más contundente.

Cuestión a tener en cuenta es la común y equivocada idea que tenemos de la Grecia antigua, como si se tratara de un solo país con un solo

* Doctor en Derecho. Miembro de la Fondation Egyptologique Reine Elisabeth Bruxelles. Profesor Tutor de Historia del Derecho en el Centro Asociado de la UNED de Portugalete (Vizcaya).

1 Finley, M.I. (edit.).: El legado de Gregia, Edit. Crítica. Barcelona, 1989.

2 llíada, XXIII, 581/585. 
gobierno. Habida cuenta de que la realidad fue la existencia de ciudadesEstado, no es extraño que frecuentemente estuviesen enfrentadas en pos de una hegemonía sobre las demás. Asi se explica que cada «polis» griega fuese un mundo muchas veces ajeno al resto, contribuyendo a dificultar el desarrollo de un sistema legal que fuese común. No existía una «ley griega». En todo caso había normas propias de cada «polis» ${ }^{3}$ como lo demuestra la inscripción del siglo $v$ a.C. que indica cómo las "polis» de $\mathrm{K} \alpha \lambda \varepsilon_{0}$ (Caleo) y E $\alpha \nu \tau \varepsilon \alpha$ (Eantea), de la región de $\Lambda$ okpt $\delta \varepsilon$ (Lócride), en la Grecia central, acordaron aplicar una misma ley para aquellos casos de detención injusta que se presentaran. Estas ciudades, separadas $10 \mathrm{~km}$., acordaron que los ciudadanos de cada una de ellas, que residieran en la otra por un tiempo superior a un mes y cometiesen un delito, fuesen juzgados precisamente por el procedimiento legal del Estado huésped, con lo que una misma ley servía para un perímetro jurisdiccional de, al menos, 10 kilómetros.

Atenas puede ser un ejemplo a seguir en el estudio del derecho griego, ya que esta ciudad-Estado dispuso de un estrecho control jurisdiccional sobre los extranjeros que fuesen demandados, al tener que verse allí los procesos que iniciaran contra ellos. Consecuencia de esa «concentración jurisdiccional» en la metrópolis fue que aquellas ciudades-Estado dependientes de Atenas, perdieron la potestad, por ejemplo, de inflingir la pena de muerte.

Entre los siglos v y IV a.C. Atenas tuvo leyes que prohibían a sus ciudadanos transportar grano a cualquier parte que no fuese la propia ciudad, así como también el préstamo dinerario a buques con rumbo a otros lugares que no fuesen Atenas ${ }^{4}$. Naturalmente era necesario un control riguroso para su cumplimiento que, precisamente vino a realizarse a través de los «guardianes del Helesponto», controlando el grano procedente de los buques que llegaban del Mar Negro. La salvedad fue el Decreto del $434 / 433$ a.C. que obligaba al pago del $10 \%$ de la carga, como tributo.

El conocimiento de Demóstenes y Menandro es necesario si queremos acercarnos, aunque sea superficialmente, a las instituciones del derecho

3 HoRnBlower, S.: El mundo griego (479/323). Edit. Crítica. Barcelona, 1985.

4 Vid. HONBLOWER, S. (nota anterior) y también Demóstenes en Discursos, XXXIV, 37 y XXXV, 51. Como se sabe orador, político y abogado griego. Nació en el demo de Peania en el 384 a.C. Encarnizado enemigo de Filipo, se suicidó con la ingestión de veneno para no caer en manos de Antípatro el año 322 a.c. 
griego. Así el primero nos lega noticias sobre el derecho ático del usufructo, uso y habitación, derechos reales de garantía y préstamo, y derecho mercantil marítimo; y el segundo fundamentalmente en derecho de familia.

No menos importante en la Grecia clásica es la institución del arbitraje privado, a través de los Kpı $\varepsilon \sigma$ (Krites o árbitros), como un servicio alternativo al ejercido por los jueces, es decir una labor extrajudicial de resolución de conflictos, como sabemos por Demóstenes ${ }^{5}$ y que frecuentemente se celebraba en templos y santuarios, sobre todo en el Theseum, cerca del Ágora. Así en "Contra Apaturio", Demóstenes nos dice que la cuestión fue encomendada a un solo árbitro, Aristocles, pero que Parmenonte que resultó condenado, no lo reconoce alegando que recurrieron a 3 y no a 1 solo, en una primera redacción contractual que quedó nula, no habiendo una segunda, y por tanto tampoco nuevo arbitraje, no obstante lo cual, Aristocles dictó un laudo contra todo derecho. Aduce pues el acusado una excepción contra el proceso judicial en el que se encuentra.

Estos procedimientos arbitrales son muy frecuentes en el derecho ático. Independientemente a que el citado discurso sobre el proceso comercial no sea atribuible a Demóstenes, ni mucho menos una magnífica pieza de oratoria forense, como indica en su introducción Colubi Falcó ${ }^{6}$ eso no impide su interés para quienes nos preocupamos por la historia del derecho antiguo, y los compromisos de arbitraje privado en esos derechos.

Árbitros podían ser aquellos ciudadanos que tuviesen como mínimo 60 años y su labor consistía en procurar la transación extrajudicial «inter partes" que evitara la posibilidad de un litigio ante los tribunales, dictando un laudo que, si era aceptado, cancelaba la causa. En caso contrario el laudo, junto con la causa que lo había originado, era lacrado y enviado al tribunal para la resolución judicial del conf́icto.

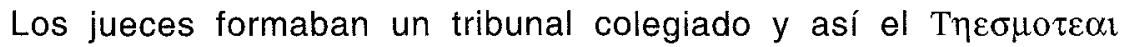
(Themosteai) estaba compuesto primitivamente por 6 arcontes encargados de la redacción, y despues de la custodia de las leves. Otro tipo de

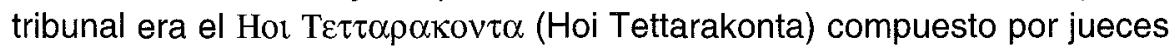
itinerantes que recorrían los $\delta \varepsilon \mu o \sigma$ (demos) áticos para juzgar los plei-

\footnotetext{
5 Demóstenes. Discursos. «Contra Afobo». I, XVII 1.

6 Idem, «Contra Zenótemis, excepción». Discursos privados, t.I. Edit. Gredos. Madrid, 1983. (Las introducciones y notas son de J.M. ColuBi FALCó.)
} 
tos, en cuya sentencia se condenaba a una sanción pecuniaria superior a 10 dracmas.

Las partes en litigio también podían llegar a acuerdos o convenios económicos estableciendo la suma con que quedaba zanjado el asunto.

Los juicios eran públicos y una empalizada separaba a jueces, litigantes y funcionarios, de los asistentes al proceso. Para ejercitar sus acciones ante la justicia los demandantes disponían de plazos tasados cuya preclusión impedía el futuro ejercicio de la acción. Los oradores, o lo que hoy denominamos defensa de las partes, disponían de un tiempo también tasado por la medida contenida en un reloj de agua o "clepsidra", y que no podian superar en cada intervención. Los jueces escuchaban sin interrumpir a los oradores y los testimonios que presentaban. En principio fueron orales y ya en tiempos de Demóstenes los testimonios eran documentos escritos y podían ir acompañados de un juramento. También en el periodo probatorio cabían los testimonios orales o escritos, los documentos que se quisiesen acompañar y otro tipo de evidencias, incluso los indicios. Por ejemplo, los documentos que constituían un gravamen sobre un bien inmueble se depositaban por quien los tenía, en manos de un tercero con lo que era un modo de recurrir a su publicidad, para aquellos casos en que la ley no obligaba. También se recurría a la colocación de nopor (horoi o mojones) con inscripciones alrededor del inmueble. Aquella sentencia que no se cumplía voluntariamente podía ser de inmediato ejecutada.

Para el ejercicio de cualquier tipo de acción ante los tribunales se necesitaba tener 18 años cumplidos. En cuanto a la causa pública, el demandante o acusador que no obtuviese $1 / 5$ de los votos del tribunal era condenado a una multa y a la $\alpha \tau 1 \mu 1 \alpha$ (atimía) o privación de sus derechos como ciudadano. Si la causa era de derecho privado y el demandante la perdía, tenía que abonar al demandado un óbolo por cada dracma que hubiese reclamado, es decir una cantidad equivalente a 1/6 de la $\varepsilon \pi \circ \beta \varepsilon \lambda t \alpha$ (epôbelia) o suma en que se cifraba el litigio.

El derecho mercantil recogía las normas a aplicar a comerciantes y navieros, para aquellos daños producidos con motivo de la navegación, y cuyas acciones tenían que ejercitarse ante los $\tau \varepsilon \mu o \sigma \tau \varepsilon \tau \alpha l$ (temóstetas), es decir un órgano colegiado compuesto por 6 arcontes y creado para el desempeño de aquellas funciones judiciales que no estaban especialmente atribuidas a los arcontes rey (cuyas funciones eran de carácter religioso, y por tanto sus competencias judiciales se limitaban a los litigios derivados de la liturgia), epónimo y polemarco (que siendo jefe del ejército sus com- 
petencias judiciales correspondían a materias hereditarias, incluidas las hijas herederas de metecos).

Entre muchas instituciones del derecho marítimo griego, es conocido el préstamo mercantil o préstamo a la gruesa, que posteriormente habrían de copiar los romanos dándole el nombre de «fenus nauticum» 7.

Figuras como la hipoteca (cuya segunda hipoteca estaba legalmente prohibida, a no ser que mediara la conformidad del primer acreedor hipotecario), el pacto de retroventa, el citado préstamo marítimo, la autonomía de la voluntad, el derecho de redención, la confiscación de bienes, el albaceazgo y tantas y tantas figuras conocidas de nuestro derecho actual, fueron conocidas y utilizadas en el derecho griego.

Autores como Isócrates (A demónicos, 36) o Aristóteles (Política III, $8,2)$ nos dicen que la voluntad del rey es la ley porque «el rey es la ley». $Y$ Estobeo (Florilegio VII, 61,10) pone en boca de Diotógenes «El rey es la ley viva». Dice Préaux ${ }^{8}$ que sobre la legislación real debemos limitarnos a los Lágidas, por cuanto son los únicos reyes para los cuales poseemos una documentación mínimamente consistente gracias a los papiros que se han encontrado y traducido.

Así como en el mundo griego el rey poseía el poder de jurisdicción en su calidad de jefe del ejército en campaña, en el Egipto ptolemaico (que es el modelo helenístico mejor conocido) el monarca lágida era juez, legislador y detentador del poder ejecutivo al mismo tiempo.

Con respecto a la práctica jurisdiccional, 3 tipos de tribunales se pueden considerar: El $\delta t \chi \alpha \sigma \tau \varepsilon p \imath o v$ (dicasterión) que era un tribunal de modelo urbano, colegiado y formado por 10 personas ejerciendo funciones arbitrales, que se convocaba por un funcionario real o $\sigma \tau \rho \alpha \tau \varepsilon \gamma o \sigma$ (estrategos), y conocía de las causas que le presentaran los emigrantes griegos, o generalmente no egipcios, entendiendo del derecho contenido en los decretos reales, y ante las lagunas que pudiesen presentar, por el derecho de las ciudades, y por último cuando también faltaba, aplicando el derecho de equidad u opinión más justa.

Había también un tribunal de $\Lambda \alpha o k p \iota \tau \varepsilon \sigma$ (laocrites), formado por jueces egipcios y para las causas que presentaran los ciudadanos egipcios, que aplicaba la ley del país o derecho egipcio.

Demóstenes. Discursos. Edit. Gredos. Madrid, 1983.

8 Preaux, C.: El mundo helenístico. Edit. Labor. Barcelona, 1984. 
Un tercer tribunal estaba formado por 3 jueces y un introductor de causas que debía tener la condición de griego. Era el tribunal de los $\mathrm{X} \rho \varepsilon \mu \alpha \tau \tau \tau \varepsilon \sigma$ (crematites), en lengua griega, y que en principio fueron itinerantes para después asentarse definitivamente en los distintos nomos del país, juzgando en asuntos reales, fiscales y privados.

Volviendo a Atenas, a partir del siglo IV a.C. se elaboró una legislación a la que había que remitirse a la hora de dirigirse a los tribunales, concre-

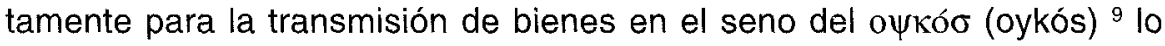
cual no impide pensar que disposiciones legales muy diversas hayan podido ser elaboradas desde el nacimiento de la ciudad como tal, puesto que el derecho no es otra cosa que la resultante de costumbres que, a través de los tiempos, se las reconoce el valor de ley.

Para un estudio más amplio de la problemática que planteaba en la práctica el derecho marítimo, la tutela o los contratos privados, hay que ir a Demóstenes, que en sus discursos privados trata tan ampliamente este autor.

Además, como dice Mariagrazia Bianchini ${ }^{10}$ la expresión "derecho helenístico" se puede interpretar en dos sentidos: Uno, como la utilización y adaptación de sus instituciones en un amplio contexto espacial; es decir, en los territorios que ocuparon las monarquías helenísticas, o sea el grupo grecomacedonio que se mantenía inmune a los derechos locales, y otro como la ordenación jurídica vigente en cada momento en esas monarquías.

Ya en el siglo III a.C. la legislación ptolemaica en el Egipto recién conquistado favoreció un sistema de coexistencia de las dos tradiciones jurídicas, la griega y la egipcia, difundiendo a la vez instrumentos y técnicas documentales griegas. Ptolomeo Evérgetes II dictó un Decreto sobre la competencia de tribunales, en los pleitos que se suscitaran ante ellos, dependiendo de la lengua usada por los contratantes. $Y$ así los documentos redactados en lengua egipcia debian ser juzgados por los tribunales laocrites y los redactados en lengua griega por los tribu-

9 Término de significado complejo que expresa hacienda, casa, en el sentido más amplio; es decir, el terreno y todo lo que hay en él, sea agrícola, ganadero, bienes muebles y personas, sean libres o esclavas. En tal sentido es también el conjunto de miembros entre los que existía una solidaridad moral y material y una vocación de reciprocidad hereditaria.

10 BiANCHINI, M.: «La transforrnación de la sociedad". Historia y civilización de los griegos. T, VIII. Edit. Icaria-Bosch. Barcelona, 1983. 
nales crematites, como ya he citado más arriba y tuve la oportunidad de acreditar ${ }^{11}$.

Un soporte escrito en el que se registraban las transacciones y negocios jurídicos, como prueba documental, era ya común en la Grecia del siglo III a.C., y fundamentalmente en el Egipto ptolemaico, como lo acredita el papiro Elefantina 1, del año 312/311 a.C., y cuya expresión jurídica es una $\Sigma \psi v \gamma \rho \alpha \pi \eta \varepsilon \varepsilon \xi \alpha \mu \alpha \rho \tau \psi \rho \circ \sigma$ (Syngraphé examártyros), estando a cargo

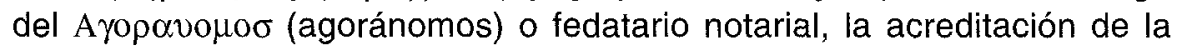
exactitud y veracidad de su contenido. Parecido, en el campo del documento público, era el $\Sigma \psi v \chi \eta \eta \rho \varepsilon \sigma i \sigma$ (synchóresis) o documento que ponía fin a un litigio, y que quedaba registrado en la oficina del $\alpha \rho \chi \eta 1 \delta \iota \kappa \alpha \sigma \tau \varepsilon \sigma$ (archidikastés).

Respecto a las instituciones jurídicas debemos indicar la importancia que tenía el derecho de las personas, libres y esclavos, estos últimos con una capacidad exclusivamente restringida al campo de la relación privada con sus amos, así como el derecho de familia, que se modifica notablemente a raíz de la desaparición del oykós, influido por las disposiciones ciudadanas de la Grecia clásica, y que con la evolución de los conceptos políticos, devienen nuevos conceptos de la familia estricta en detrimento de la amplia. El derecho hereditario será una consecuencia de lo dicho anteriormente y en cuanto al derecho de cosas conformó la determinación de los derechos reales, fundamentalmente el derecho de propiedad. De no menos importancia, por las transacciones comerciales y privadas, será el derecho de obligaciones, y como colofón de todos, la administración de justicia.

En el derecho de la Grecia antigua una de las fuentes fundamentales para conocer la condición femenina son, precisamente, los poemas homéricos. Más tarde, en la época arcaica (siglos vIII a vI a.C.) Jenofonte ${ }^{12}$ Demóstenes ${ }^{13}$ Platón ${ }^{14}$ Aristofanes ${ }^{15} \mathrm{y}$ por último en los comienzos de

11 Alonso y Royano, F.: El derecho de familia en el Egipto faraónico. Edit. Lepsius. Valencia, 1995. También Tesis Doctoral (Instituciones familiares en el Egipto faraónico). UNED. Madrid, 1994.

12 JenOFONTE. Memorables II. 7,6. Económico X 2,5 Madrid, 1980.

13 DEMÓSTENES. Discursos. «Contra Boeto» 1, 27. «Evergo y Mesíbulo», 55, 56. «Espudias», 3 , 4,9. «Eubúlides», 35, 45, «Aristócrates», 53. «Macártato», 54. «Afobo», 1, 45. «En defensa de Formión», 14. Edit. Gredos. Barcelona, 1963.

14 Platón. Leyes. Barcelona, 1972.

15 ARISTÓfANES. Comedias (Lisistrata). Madrid, 1974. 
nuestra Era, Plutarco ${ }^{16}$. Estos autores son los que mejor nos informan respecto a la institución matrimonial y familiar. Entre los autores modernos cabe destacar a Garnet ${ }^{17}$ Vernan ${ }^{18}$ Preaux ${ }^{19}$ y Finley ${ }^{20}$.

Otro aspecto, típico y no menos importante, es el «silencio femenino griego en su historia», y la vertiente de la lejanía institucional de la mujer, que no obstante era transmisora e interlocutora oracular de los dioses, como felizmente nos ha descubierto la profesora Iriarte ${ }^{21}$. Este papel fundamental de interpretación e intermediación femenina en el universo del discurso griego, y su labor híbrida de $\pi$ nove (voz) y oro $\pi \varepsilon$ (silencio) que tan acertada y profundamente nos describe esta autora, nos ha servido como parabólico espejo, captador de una imagen de mujer griega que nosotros desconocíamos y que, sin duda nos ayudará en la comprensión de la institución familiar.

Todo ello nos sirve de marco comparativo entre universos femeninos griegos y otros de la antigüedad, como el egipcio, babilónico e incluso hitita, y en ese vector comprobar si los modelos del comportamiento cotidiano de la mujer se entremezclan, o por el contrario, divergen. Esto último es lo que parece más cierto, cuando menos en determinados aspectos jurídicos y sociales. Concretamente la mujer egipcia, además de sacerdotisa, de esposa y madre de dioses (el ejemplo de Ahmosis Nefertari es paradigmático), era madre y esposa de hombres, con los que en algunas épocas históricas, comerciaba y pleiteaba. No tenemos más que acercarnos al papiro Brooklyn 35/1446, donde una esposa, del Imperio Medio, con plena capacidad legal, independientemente de su marido, plantea una demanda a su padre, en defensa de sus propios intereses. La situación de la mujer egipcia (con haber «inventado" los griegos, según dicen, la democracia) fue mucho más democrática e igualitaria, sin duda y dentro de amplios momentos y situaciones históricas, que la mujer griega.

\section{EL DERECHO DE FAMILIA Y MATRIMONIAL}

Si hemos de creer a Jenofonte en "Económico", en el diálogo que mantiene Iscómaco con Sócrates (VII, 11), aquél expresa a su esposa:

\footnotetext{
Plutarco. Vidas paralelas. Madrid, 1978.

GARNET, L.: Marriages de tyrans. París, 1968.

VeRnANT, J.P.: Le mariage. París, 1974.

PreAux, C.: Le statut de la femme a l'epoque hellenistique, principalement en Egypte. París, 1959.

FINLEY, M.I.: Marriage. Sale au Gif in the Homeric World. Bruxelas, 1955.

IRIARTE, A.: Las redes del enigma. Voces femeninas en el pensamiento griego. Madrid, 1990.
} 
«Ninguno de los dos, ni tú ni yo, estábamos impacientes por encontrar a alguien con quien dormir. Pero después de haber reflexionado, yo por mi cuenta y tus padres por la tuya, sobre cuál sería la mejor compañía que podríamos tomar para formar un hogar y tener unos hijos, yo por mi parte te he escogido a ti y tus padres, a lo que parece, me han escogido a mí entre los partidos posibles». Aquí se ve cómo la mujer griega del siglo $v$ a.C. no tenía libertad para escoger marido. Era sin duda, en el aspecto jurídico, una menor de edad, y por tanto con una fuerte limitación de derechos que, sin embargo, eran reconocidos al varón («yo por mi parte, te he escogido a tì»). La formación del hogar, la procreación y la adecuada gestión del oykós, parece que fueron tareas primordiales en la condición femenina en Atenas, y se puede decir que no se aprecian diferencias entre la esposa de Iscómaco y la de Ulises, 4 siglos antes. También estaba excluida de los tribunales (aunque esto parece ser la tónica común en las culturas antiguas, si prescindimos de la mujer egipcia) y tal situación jurídica de minoría de edad se nos presenta como indiscutible, por la necesidad que tiene de un $\kappa \psi p$ io $\sigma$ (kyrios) o tutor legal ${ }^{22}$ a lo largo de su vida, a través de su padre o hermanos, mientras está soltera; o de su esposo, hijos o parientes cercanos, a lo largo de su matrimonio o viudez.

Como anécdota curiosa diremos que en los prolegómenos del matrimonio se daba una costumbre que consistía en encerrarse los novios y comer juntos un membrillo, con objeto de suavizar el aliento a fin de que las primeras efusiones amorosas no resultaran desagradables. Esto es una evolución que corresponde al período clásico, porque en el más arcaico según dice Hentze ${ }^{23}$, el beso en la boca era desconocido y para el saludo se besaban en la cabeza, los ojos y rara vez en las manos. Cuando se besaba en la frente a la persona amada se la daba, a la vez, un cariñoso tirón de orejas, según queda acreditado en Homero: «Ya no quiero a Alcipe -dice el cabrero de Teócrito_ porque la última vez que la llevé una paloma no me cogió por las orejas al abrazarme».

El contrato matrimonial era oral, a través de un compromiso establecido entre los padres de la futura esposa, o su kyrios, y el pretendiente o los padres de éste, como $\varepsilon v \gamma \psi \varepsilon \sigma 1 \sigma$ (engyesis), como hemos podido leer en "Económico», previo el consiguiente ofrecimiento de los $\eta \varepsilon \delta v \alpha$ (hedna),

22 Que custodiaba y representaba a la mujer desde la pubertad hasta el fallecimiento.

23 HENTZE, C.: Las formas de saludo en los poemas homéricos. Philologus I, XI. 
que era el conjunto de presentes ofrecidos por el pretendiente a los padres de la novia, a modo de lo que hoy diríamos «petición de mano", y la pos-

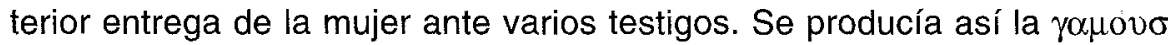

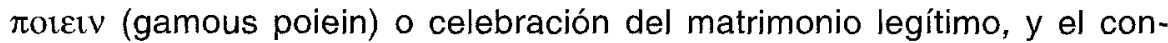
sentimiento dado por el padre del contrayente, aprobando el matrimonio recibía el nombre de $\Sigma \psi v \chi \eta o \rho \varepsilon \sigma i \sigma$ (Synchoresis). Por eso no existía expresión gramatical que designara tal situación social, ni tan siquiera institucional, como ya expresó Aristóteles. Sólo el acto consumatorio del matrimonio y, con él, la unión legítima, recibía el nombre de $\varepsilon v \gamma \psi \varepsilon$ (engye). Había pues de producirse la cohabitación, no sólo en su acepción de "vivir juntos», sino de practicar la cópula para engrendrar hijos. Esa es la pretensión legal cuando dice una norma imperativa: «La que hubiesen prometido para que fuese esposa, según normas de derecho, el padre o el hermano de un mismo padre, o el abuelo por vía paterna, de ésta haya hijos legítimos. Si no existiese ninguno de éstos, si fuese epíclera, el tutor casese con ella, pero si no lo hubiese, aquél a quien el padre la hubiese confiado, éste sea el tutor. Si no hubiese nacido epíclera y a un tiempo hubiese sobrepasado en dos años la edad viril, sea dueño de los bienes y proporcione el alimento a la madre».

El matrimonio era un compromiso o contrato totalmente privado que pertenecía a ese tipo de derecho y que no quedaba formalizado por medio de ningún registro de carácter institucional, ni protegido por sanción jurídica alguna. Pero eso no significaba que la consideración de «status matrimonial» no fuese válida y legítima a través de la $\varepsilon \kappa \delta o \sigma l \sigma$ (ekdosis), es decir la ceremonia que tenía por objeto la entrega de la mujer como esposa legítima, de manos del kyrios al marido, y como decimos, cuya transmisión determinaba el traslado de aquélla al hogar conyugal. Para el reconocimiento de esa legitimidad se necesitaba, además del recíproco compromiso de matrimonio, la presentación de la esposa en la casa del marido (que también más tarde harán los romanos a través del «in domun deductio», como una de las formas de celebración matrimonial), y la subsiguiente cohabitación o $\gamma \alpha \mu$ o $\sigma$ (gamos), es decir la cópula carnal. Desde entonces el matrimonio adquiría rango de tal, deviniendo válido y la mujer adquiría el rango de $\gamma \alpha \mu \varepsilon \tau \varepsilon \gamma \psi v \varepsilon$ (gameté gyné), o esposa legítima. En el mismo sentido se expresa Mosse ${ }^{24}$ cuando cita como esposa legítima a la $\alpha \lambda \circ \chi \eta \circ \sigma$ (álochos). 
El matrimonio legítimo sólo existía en el caso de que ambos esposos tuviesen la ciudadanía ateniense, es decir haber nacido de padre y madre ateniense, no pudiendo contraer matrimonio los hermanos uterinos pero sí los procedentes de distinta madre. $Y$ al conjunto de bienes, que podían componerse de las más diversas cosas y esclavos, pertenecientes a la mujer como privativos y no formando parte de la dote que llevara al matrimonio, se los conocía como $\pi \alpha \rho \alpha \pi \eta \varepsilon \rho v \alpha$ (paraferna).

En tiempos de Pericles una ley prohibia el matrimonio de ciudadanos con extranjeras. Su incumplimiento se sancionaba con la venta como esclavo de aquel cónyuge que tuviese la condición de extranjero y con una multa de 1.000 dracmas al ateniense. Así decía esa ley: «Si un extranjero cohabitare con una ciudadana por cualquier medio o artificio, denúncielo ante los tesmótetas el que quisiere de los atenienses a quienes les es lícito. Si fuere condenado, sea vendido él y su hacienda, y la tercera parte sea de quien hubiese conseguido la condena. Sea también si la extranjera cohabitare con el ciudadano según las mismas normas, y el que cohabitare con la extranjera que hubiese sido condenada deba 1.000 dracmas». A tal punto llegaban los soberbios e insolidarios griegos promoviendo la pureza de su sangre para que no fuese contaminada con quien no fuese demócrata ciudadano, prohibiendo no solamente el matrimonio sino la simple cohabitación.

«Si alguien hubiere dado en matrimonio — decía otra ley prohibitiva similar al caso anterior - una mujer extranjera a un varón ateniense, como si fuese pariente suya, átimo sea y su hacienda sea pública, y la tercera parte, de quien hubiese conseguido la condena. Presenten la acusación pública ante los tesmótetas aquellos a quienes es lícito, como en la usurpación de ciudadanía».

Con referencia a la edad para contraer matrimonio, no había límites, aunque sí impedimentos de orden real o físico, puesto que hasta en tanto no se consumara el matrimonio, no era válido. Los supuestos limitativos o impedimentos eran los siguientes:

a) Cuando la futura esposa era una niña. Tal es el caso histórico de la hermana del orador Demóstenes, prometida por su padre cuando solo contaba 5 años de edad.

b) La mujer soltera que fuese $\varepsilon \pi\llcorner\kappa \lambda \varepsilon \rho o \sigma$ (epíkleros), es decir única heredera del caudal hereditario paterno, y sobre la que pesaba la obliga- 
ción de contraer matrimonio con el $\alpha v \chi \eta\rceil \sigma \tau \varepsilon v \sigma$ (anchisteus) o pariente más próximo de la rama paterna. La pretensión jurídica perseguida no era otra que la de que los bienes del caudal no saliesen del oykós familiar. El problema solía plantearse cuando uno de los dos obligados había contraído anterior matrimonio.

Puede que esa ley sea la que cita Plutarco en su «Vida de Solón» (640/558 a.C.) que ha pasado a la historia como legislador y reformador ${ }^{25}$ por haber dado a los atenienses leyes y abolido las de Dracón, que por su dureza han llegado hasta nosotros con el sobrenombre de "draconianas", cuando el autor citado dice: «Decretó una ley por la que la heredera casada con un impotente podía ayuntarse con los parientes de éste, al objeto de que los previsibles hijos fuesen del mismo linaje». De cualquier modo el fin perseguido es el mismo.

Demóstenes nos transmite en "Contra Macártato", XLIII, 51, la siguiente ley: «Respecto de las epícleras que pagan el censo de los jornaleros, si no quisiese casarse el de más cercano parentesco, déla en matrimonio con una dote, el $\pi \varepsilon v \tau \alpha \chi 0 \sigma o \mu \varepsilon \delta u \nu o$ (pentacosiomedimno) de 500 dracmas; de 300 el caballero, y de 150 el yuntero, además de sus bienes personales. Si hubiere más en el mismo grado de parentesco, cada uno dote a la epíclera según su parte alícuota. Si las mujeres fuesen más, no sea obligatorio para uno solo dar en matrimonio más que a una, sino que el más próximo la dé o se case con ella. Si no se casare el más cercano en parentesco o no la diere en matrimonio, el arconte compélalo a casarse con ella o darla en matrimonio. Si el arconte no le compeliere, incurra en multa de 1.000 dracmas consagradas a Hera. El que quiera denuncie ante el arconte a quien no cumpliese estas prescripciones».

Otra ley contemplaba: "Sortee el arconte las demandas por herencias y epícleras durante cuantos meses hay, salvo el de esciroforión ${ }^{26}$. No se posea herencia no atribuída judicialmente».

c) La mujer cuya nacionalidad se pusiese en duda (Condición ateniense o extranjera, con un diferente tratamiento jurídico, como hemos tenido ocasión de ver más arriba).

25 También, según DEMÓsTENES, legisló Solón sobre las distancias a guardas en las relaciones de vecindad, y que, de acuerdo con Colubi Falcó, "al parecer inspiraron la normativa romana" (vid Digesto $X, 1,13$ ).

26 Era el último mes del año ateniense y el arconte cesaba en sus funciones judiciales, de modo que la instrucción judicial del asunto que hubiese comentado, cesaba. 
De todo lo anterior se desprende que el fin último del matrimonio griego era la conservación y posible incremento de la propiedad de bienes patrimoniales a traves de la procreación de hijos legítimos destinados a la herencia. De otro lado no puede olvidarse el fin político, transcendente a la largo de la humanidad, de consecución contractual de pactos e intereses, incluso estratégicos, entre clanes, familias y fortunas. Tenemos el ejemplo de Alejandro que "casó a la mayor parte de sus oficiales de alta graduación con las bellas hijas de la más acrisolada aristocracia, y dio a 10.000 de sus soldados el permiso y la dote para casarse con mujeres persas. Conjuntamente con las fiestas de las bodas de Susa, Alejandro instituyó unos 10.000 pequeños puestos de vigilancia militar para que sirviesen a la causa de la paz ${ }^{27}$.

En el sistema modélico griego, la esposa legítima que se tuviese por respetable ni asistía a banquetes, ni hablaba en público. $Y$ si ciertamente la elección de cónyuge frecuentemente se encontraba mediatizada por intereses materiales de orden económico o socio-político, hasta el extremo de que la mujer veía a su esposo por primera vez el día de la boda, no es menos cierto que también había contracciones matrimoniales presididas por el amor. Sin ir más lejos al amor lo tenemos como principal protagonista de algunas obras de la comedia griega. Concretamente en Menandro.

Aunque parece que la monogamia fue la norma general en el derecho griego, no era obligatoria puesto que existía la institución del concubinato, admitiéndose socialmente la $\pi \alpha \lambda \lambda \alpha \kappa \varepsilon$ (pallaké) ${ }^{28}$, y no considerándose delito de adulterio.

La ruptura de la convivencia en las crisis matrimoniales presentaba 4 situaciones: La separación; el abandono; el repudio y el divorcio.

La separación se daba simplernente como un fenómeno temporal, voluntario o forzoso. Podía darse como una medida cautelar, ante una aparente incompatibilidad conyugal que no pretendía romper el vínculo matrimonial, o como una medida forzada por las circunstancias, bien originada

Banm, P.: Alejandro Magno y su tiempo. Gütersloh (Alemaia), 1968.

28 Concubina introducida en casa del esposo, sin atadura ni protección jurídica con lo que la unión era en cualquier momento revocable. Generalmente solía tratarse de jóvenes humildes o de esclavas. 
por el viaje necesario de cualquiera de los cónyuges (con las vicisitudes, peligros y lentitudes de cualquier viaje, terrestre o marítimo en aquellas épocas) o por la participación del varón en una expedición guerrera. Tal es el caso de Ulises, o el de los combatientes que describe la lliada. Sin embargo como remedio institucional con sanción jurídica de obligado cumplimiento, creando un status jurídico, no se conocía.

El abandono era un repudio disimulado, unilateral, generalmente promovido por el varón y sin sanción jurídica alguna. Pero hay ejemplos históricos donde el repudio proviene de la mujer. Tal es el caso de Timea, esposa legítima de Agis, rey de los lacedemonios, que cometió adulterio con Alcibíades, según nos cuenta Plutarco en la vida de éste. A este respecto y desde la óptica jurídica, es discutible el probable abandono sin causa del esposo, cuando este autor nos dice: «Habiendo habido un terremoto, él, de miedo, saltó del lecho y del lado de su mujer y después de 10 meses no se ayuntó con ella, y como después de ese tiempo hubiese nacido Leotíquides, no le reconoció por hijo suyo, y por esta causa fue despues Leotíquides privado de suceder en el reino ${ }^{29}$.

Aquí parece que hay un claro caso de adulterio por parte de la mujer (independientemente del motivo que diese su marido). Y quizás podría aplicarse la regla que Esquines, en «contra Timarco», 183, atribuye a Solón: "Cuando hubiese aprehendido al adúltero, no sea lícito al que lo hubiese aprehendido cohabitar con la mujer; si siguiere cohabitando, átimo sea ${ }^{30}$. Tampoco sea lícito entrar en los templos públicos a la mujer sobre la que hubiese sido aprehendido un adultero; si entrare, impunemente sufra lo que sufra, salvo la muerte". Lo que ocurre es que dudo que los lacedemonios aplicaran las leyes atenienses y menos a sus reyes.

No sólo entre esposos y pallakés tenían cabida las relaciones amorosas, sino en las extramatrimoniales que, mantenidas con algunas amantes, originaban una perturbadora problemática en la familia legitima, cuyos adulterios provocaban incluso un auténtico desamparo familiar. Ése es el caso de Mantias ${ }^{31}$ el de Perícles con Aspania, citado por Plutarco. Por su parte Lisias, en el discurso que hace en «Defensa de la

29 Plutarco. Vida de Alcibiades. XXIII, 343.

30 Es decir, se le impedía ser testigo en dichos procesos. Esta prohibición recibía el nombre de $\alpha \tau \mu \mathrm{t} \alpha$ (atimía).

31 Demóstenes, «Contra Boeto», 1, 27. 
muerte de Eratóstenes" nos proporciona el conocimiento legal respecto al adulterio en Atenas y el pretexto legal de permitir la muerte del cómplice de la adúltera que hubiese sido sorprendido en flagrante delito, sin necesidad de promover un proceso previo. Pretexto que ha tenido virtualidad hasta hace 40 años en nuestro Código Penal, a través de la figura del uxoricidio.

Para ejercitar un proceso por adulterio el derecho griego disponía de la acción pública $\Gamma \rho \alpha \pi \eta \varepsilon \mu o \imath \chi \eta \varepsilon \imath \alpha \sigma$ (Graphé moicheias), es decir «crimen de adulterio" (moicheia). Téngase en cuenta que, generalmente era considerado adulterio el cometido por la mujer, puesto que el cometido por el marido sólo estaba considerado como tal figura punible el cometido con la esposa legítima de otro ateniense.

El repudio era una institución cuasi-masculina, aunque cuando lo realizaba el marido a través de una $\delta$ i $\varepsilon \varepsilon \xi o v \lambda \varepsilon \sigma$ (diké exoûlês), esto es una expulsión ilegal, la ley le obligaba a restituir la $\pi \rho 01 \xi$ (proix) o dote, o en caso contrario, pagar como interés 9 óbolos por el tiempo de retraso. De modo que aquella expulsión de la mujer del hogar conyugal recibía el nom-

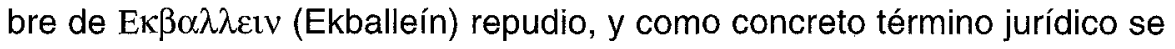

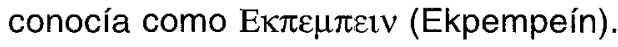

El divorcio era vincular y producía la ruptura matrimonial entre ambos esposos, proviniese la motivación de cualquiera de ellos, originando el cumplimiento de determinadas obligaciones a través de sanción jurídica en orden a contemplar la dote y la situación de los hijos, para proteger sus expectativas hereditarias, así como contemplar la libertad de los ex cónyuges a contraer un nuevo vínculo matrimonial.

Cuando el divorcio se promovía por mutuo consenso la ley contemplaba la devolución de la proix o dote al padre o kyrios de la mujer, puesto que precisamente la dote era un elemento conformador del derecho matrimonial griego, cuando menos en la época clásica. Dote que sólo podía ser usufructuada por el marido, al que el kyrios de la mujer, a modo de garantía devolutoria, imponía una $\alpha \pi 0 \tau \iota \mu \alpha$ (apotíma) o hipoteca sobre los bienes de aquél.

En algunos casos la ruptura era unilateral, generalmente por parte del esposo, con lo que el divorcio adquiría firmeza cuando éste devolvía mujer y dote a su suegro o kyrios. Se exigía una condición: La promesa de nuevo matrimonio de la mujer, a fin de dar utilidad a la dote y evitar un proceso judicial acusatorio de mala administración dotal. 
Históricamente conocemos casos de divorcios promovidos por la esposa ${ }^{32}$ aunque era lo excepcional, debido a que, en principio, sólo se encontraba capacitado el kyrios para presentar la demanda y entablar el proceso de divorcio. Plutarco nos dice: «que si la ley prescribe que la mujer que quiere abandonar a su marido se presente ella misma ante el magistrado, es para dar al marido la oportunidad de reconciliarse con ella y retenerla junto a él». Por otro lado recordando que el kyrios de la mujer era su propio marido, desde la contracción matrimonial legítima, ese propio marido debía presentar ante los tribunales la demanda de divorcio, o ante su negativa, el padre de la mujer, el hermano o el pariente más cercano, y por ese orden.

Si bien en la Grecia clásica no se elaboró un corpus jurídico a la manera posterior de Roma, en Atenas y por lo menos desde el siglo $v$ a.C. existían, como se está viendo, normas jurídicas en las que apoyar un «petitum" del justiciable ante los tribunales y estando normada tanto el destino de la mujer epíclera, divorciada o viuda, como la transmisión de los bienes del caudal hereditario o la situación legal de los hijos, a través de acciones judiciales que vamos a comentar.

Así se contemplaba en el derecho sucesorio la expectativa de derechos hereditarios: «Lo que, habiendo hijos legítimos, el padre hubiere testado, si hubiera muerto sea firme su testamento, habiendo los hijos sobrepasado en dos años la edad viril». Otra ley griega decia: "Cualquiera que hubiese muerto sin haber otorgado testamento, si hubiere dejado hijas, con éstas (es decir, la herencia, a la que va unida la epíclera, y ha de ser desposada por el pariente más próximo), pero si no, sean dueños de sus bienes los siguientes: si hubiere hermanos de un mismo padre; y si hijos legítimos de hermanos, obtengan la parte de su padre; si no hubiere hermanos o hijos de hermanos sus descendientes obténganla según las mismas reglas; tengan preferencia los varones e hijos de varones, siempre que fuesen descendientes de los mismos, aunque estuviesen más lejos en parentesco. Si no los hubiere por vía paterna hasta hijos de primos, sean dueños los de la vía materna según las mismas reglas. Si no los hubiere dentro de estos grados ni por un lado ni por otro, sea dueño el más próximo por vía paterna. Ni para bastardo ni para bastarda haya

32 Tal es el caso de Hipareta, mujer del prestigioso político Alcibíades, en el siglo v a.C., y cuyo conocimiento nos lo ha transmitido Plutarco. 
derecho sucesorio ni a los bienes religiosos ni a los profanos desde el arcontado de Euclides ${ }^{33}$.

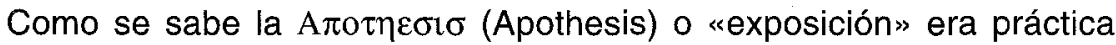
consagrada por el uso y tolerada por el derecho griego, por la cual se abandonaba al hijo recién nacido que no se deseaba integrar en el seno

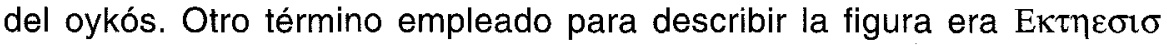
(Ekthesis). La exposición solía ir acompañada de una Гvopı $\mu \alpha \tau \alpha$ (Gnorismata) o conjunto de diversos objetos que se colocaban al lado de la criatura, y que el latín nos ha transmitido como «Crepundia». De modo que las cosas que eran halladas junto a esa criatura, en expresión griega abreviada se conocía como $T \alpha \sigma \psi v \varepsilon \kappa \tau \iota \tau \eta \varepsilon \mu \varepsilon v \alpha$ (Ta synektithemena). También solía acompañarla una serie de señales o pruebas de reconoci-

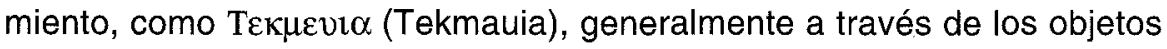
que comentamos. Así más adelante si sobrevivía tenía la posibilidad de promover una $\Delta \mathfrak{t} \varepsilon$ oi $\tau o v$ (Diké sitou) que era precisamente la acción judicial ante los tribunales por la que se reclamaba una pensión alimenticia.

En muchas ocasiones y con motivo de la tutela se producían abusos y hasta fraudes a la hora de dar cuentas al tutelado sobre sus bienes, según nos ha hecho llegar Demóstenes, en cuyos discursos ("Contra Afobo, I») vemos como podían impugnarse en un proceso judicial, si el tutelado no estaba conforme con dichas cuentas, a través de la acción $\Delta \iota \kappa \varepsilon \varepsilon \pi \imath \tau \rho \circ \pi \varepsilon \sigma$ (Diké epitropes).

En el derecho procesal griego se contemplaban para la práctica del enjuiciamiento multitud de acciones jurídicas rigurosamente formalistas.

La expresión $\alpha \pi \circ \gamma \rho \alpha \pi \eta \varepsilon$ (apographé) tanto podía emplearse para designar una demanda como un escrito de inventario, y un contrato de $\sigma \psi v-$ $\gamma \rho \alpha \pi \eta \varepsilon$ (syngraphé), era de por sí, suficiente prueba liberatoria e irrefutable de lo que las partes en él hubieren convenido. Las partes, en el litigio o antes para evitarlo, podían llegar a un acuerdo o convenio sobre sus pretensiones a través de una Ty $\mu \varepsilon \sigma \iota \sigma$ (timesis) determinando una suma dineraria para saldar, incluso, un delito.

Una acción penal por falso testimonio, que frecuentemente se utilizaba en los pleitos se ejercitaba por medio de una $\Delta \mathrm{\imath} \kappa \varepsilon \pi \sigma \varepsilon v \delta o \mu \alpha \rho \tau \psi \rho$ rov (diké pseudomartyriôn) (como se contempla en «Contra Afobo en defensa de

33 Es decir, en el 403/402 a.C. que es cuando se regulalizó el alfabeto griego. 
Fano") y una acción por daños a través de una $\Delta \imath \kappa \varepsilon \beta \lambda \alpha \beta \varepsilon \sigma$ (diké blabês, en «Contra Zenótemis»).

Spengler ${ }^{34}$ dice que entre el derecho griego y el romano no hay antigüedad sino sucesión y presupone, en el romano, las experiencias de los anteriores. Siendo así, se equivoca cuando dice que «el derecho antiguo es un derecho al día y aun del momento. Es creado en su idea, para cada caso, y en cada caso particular. Resuelto éste, cesa de ser derecho". Tanto el derecho egipcio - hay que contestarle-como despues el griego, disponian de principios jurídicos inalterables, incluso, como en el caso del egipcio, para el faraón. Los ejemplos que venimos exponiendo de instituciones que pasan de unas culturas a otras nos eximen de mayor comentario.

$Y$ por su parte Zielinski ${ }^{35}$ indica el orgullo que tenían los atenienses de su «buena legislación» que les distinguía en el campo jurídico de las naciones de sus alrededores.

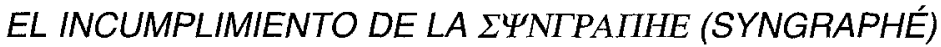 DE PRÉSTAMO A LA GRUESA Y LAS EXCEPCIONES PROCESALES EN EL DERECHO MERCANTIL GRIEGO}

El contrato de préstamo marítimo en el derecho mercantil ático contemplaba una serie de requisitos y cláusulas que trataremos de describir a través de Demóstenes, en «Contra Dionisodoro, por daños», LVI, entre otros.

En términos generales el contenido de una $\Sigma \psi v \gamma \rho \alpha \pi \eta \varepsilon$ era:

a) Contrato de préstamo dinerario.

b) Para el fletamento de un navio.

c) Del transporte de cualquier carga (en este caso, trigo).

d) Con devolución del capital.

e) Pago de intereses.

f) Cláusula penal como garantía, para el supuesto de incumplimiento.

34 Spengler, O.: La decadencia de Occidente. Vol. Il. Madrid, 1993 (págs. 77/78).

35 ZiELINSKI, T.: Historia de la Civilización antigua. Madrid, 1987. 
a) El contrato se efectuaba a través de una $\Sigma \psi v \gamma p \alpha \pi \eta \varepsilon$, es decir un contrato escrito en un soporte material duradero que puede acreditar su contenido, bien por medio de una tablilla encerada o en un papiro ${ }^{36}$, al objeto de poder desarrollar dicho contenido con determinadas cláusulas y, si fuese preciso instar su cumplimiento, o en caso contrario exigir responsabilidades por daños ante el tribunal competente. En este caso los Tع $\mu$ $\sigma \tau \varepsilon \tau \alpha \sigma^{37}$, aunque también podía haberse hecho a través de un arbitraje privado, si previamente así lo hubiesen acordado las partes contratantes, y siempre que lo permitiesen las leyes, lo que para el caso del transporte de trigo no era posible.

En el contrato deben figurar las partes contratantes. En este caso la parte prestamista, Pánfilo y Darío, y la parte prestataria, Dionisodoro y Parmenisco. El préstamo es real, de presente y bajo condición. Es decir, se entrega un dinero ${ }^{38}$ con mutuo consentimiento, perfeccionándose el contrato y siendo, por tanto, lícito. Así expresa el demandante cuando dice: «...en las leyes vuestras ${ }^{39}$ que prescriben que sean firmes cuantas convenciones haya hecho uno con otro voluntariamente...».

Es un contrato especial. Contempla un tipo concreto de contratos mercantiles cuyo tráfico es marítimo. No contempla, por tanto, un transporte terrestre sino naval. Su nacimiento y conclusión es de emporio a emporio. Esto es, de puerto a puerto.

Es un contrato de préstamo a la gruesa que, imprescindiblemente, debe contemplar como claúsula de «ius cogens»:

1. Una garantía.

2. Si el transporte es de trigo (dada la necesidad que de él había en Atenas), sólo puede desembarcarse en el puerto de Atenas. Así lo prescribían las leyes áticas ${ }^{40}$ según se desprende del texto que comentamos:

36 Así dice el texto: «...después de haber recibido un dinero visible -es decir, en efectivo, y que fueron 3.000 dracmas - y reconocido en una tablilla comprada por 2 calcos (esto es, $1 / 4$ de óbolo) y en un pequeño trozo de papiro...".

37 Órgano judicial colegiado compuesto por 6 arcontes.

38 Dice el texto «recibió de nosotros en préstamo sobre la nave, 3.000 dracmas...».

39 En «Contra Evergo y Mnesíbulo», dice: «... léeme la ley y el testimonio, la cual prescribe que sea firme lo que uno con otro haya acordado...».

40 «...en vosotros jueces y en vuestras leyes..." En este contrato que contempla el transporte de trigo, dada la penuria de éste en el 322 a.C. (fecha aprox. del contrato) estaba prohibido el transporte de trigo a otros emporios que no fuese Atenas. De modo que las responsabilidades a exigir por el incumplimlento de ese contrato, habian de hacerse ante la justicia oficial. 
«...condujo su barco hasta Rodas, y habiendo desembarcado allí la carga, la vendió, violando el contrato y vuestras leyes...».

Es decir el contrato sólo concluye cuando el flete, en este caso el trigo, se entrega en Atenas. En caso contrario se incumple el contrato (por eso es condicionado. La condición es desembarcarlo en Atenas, y no en otro emporio) y se abren responsabilidades exigibles ante el tribunal de los

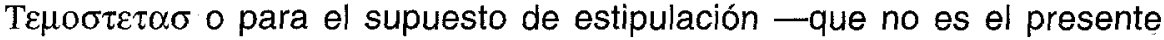
caso- ante el árbitro único o colegio arbitral).

Lo que sí parece posible, a tenor del pleito que nos está ocupando, es la posibilidad de anulación acordada del contrato -evitando así la incertidumbre de la sentencia-y dirimir el asunto ante árbitros privados que fuesen profesionales del comercio, según dice el texto: «...como para presentarse ante un árbitro, estando claro de antemano que le condenaría a pagar las sumas, siéndoles posible comparecer ante un tribunal con el dinero...».

El préstamo es dinerario (vid. nota 2). No se presta la nave, ni la marinería, ni los aparejos. Se prestan 3.000 dracmas. es decir dinero en efectivo con el que el comerciante pagará el arrendamiento de la nave al transportista, o en caso de ser éste el contratante prestatario, pagar los sueldos a marineros y remeros, el flete, etc.

b) Objetivamente se contrata un navío de carga, mercante o transporte naval y precisamente para un concreto tarnsporte, esto es, la traída de trigo desde un país exportador, probablemente Náucratis, en Egipto ${ }^{41}$. No hay que olvidar que Egipto fue el granero de Grecia antes de serlo de Roma.

Por tanto no se trata de cualquier tipo de nave: guerra, recreo, etc., sino un tipo de navíos dedicados en exclusiva al tráfico marítimo, lo que acredita la existencia de un comercio marítimo con sus particulares reglas debidamente establecidas. Esto es, un derecho mercantil y dentro de éste, un derecho marítimo acreditado por fuentes historiográficas, arqueológicas, numismáticas (posteriores), etc.

41 Dice el texto: «...Dionisodoro, aquí presente, y su socio Parmenisco, enviaron la nave a Egipto desde acá. Parmenisco navegaba a bordo del navío, pero este sujeto permaneció aquí. En efecto, eran, jueces, para que no ignoréis este detalle, todos esos servidores y colaboradores de Cleómenes, el que mandó en Egipto..." (Recuérdese que el citado fue nombrado Sátrapa por Alejandro a la conquista de Egipto). 
Siendo el trueque y comercio tan viejo como el hombre, si bien en principio no muy definido, pero concretizado y especializado más tarde, adquiere ya carta de naturaleza de manos de sumerios, egipcios, cretenses, fenicios, y después griegos, que es donde estamos, que un derecho internacional incipiente ya contempla y respeta sus reglas.

Junto a esa actividad mercantil aparecen disensiones y se arbitran soluciones reconocidas más allá de los pueblos como un «modus operandi» genérico y, por tanto, común para todos.

c) Todo lo cual no quiere decir que «sólo» transportara trigo, ya que así se desprende del texto: «...ni éste era el dueño de todas las mercancías, ni tampoco su socio, sino que los comerciantes de a bordo enviaron aquí sus géneros...(y más adelante)...¿si fletábais otros barcos, según decís, no embarcásteis en ellos todo el cargamento de la nave, sino dejásteis el trigo en Rodas?...".

De modo que una cosa es el contrato de fletamento de un navío, es decir, la posibilidad de contratar al completo el arrendamiento del navío, y otra el de una parte de él, esto es el espacio ocupado por la carga a transportar, o el transporte de una concreta y determinada carga (trigo y no otra cosa), o bien el arrendamiento de un determinado navío) y no otro (por cuestión de confianza, etc).

Éste no parece ser el caso, sino que lo común era el arrendamiento de un navío para efectuar el transporte marítimo de una carga de trigo que habría de ser descargada en el puerto de Atenas, y que en este caso adquiere una especial relevancia por ser el trigo una mercadería extremadamente apreciada por la necesidad que de ella había en el emporio, hasta el punto de que ese cereal sólo podía desembarcarse allí, y no en otro sitio, y que, protegido por leyes con carácter de «ius cogens», hacía aparecer una cláusula cuyo incumplimiento provocaba la intervención necesaria de los $\tau \varepsilon \mu o \sigma \tau \varepsilon \tau \alpha \sigma$ áticos, si se producía la denuncia judicial del contrato.

El transporte marítimo era multivario: Ánforas de aceite, vino, telas, especias, cereales, animales, esclavos, etc. El navío podía tener uno (lo más infrecuente) o más propietarios (lo más frecuente), quienes lo dedicaban al transporte a través del contrato de arrendamiento.

Lo que no sabemos con certeza es, si el arrendamiento de aparejos y marinería se hacía en conjunto con el casco, o se hacía de modo independiente. Sí sabemos que el arrendamiento era para el traslado de la 
carga desde su punto de origen en el país exportador, hasta el emporio importador, es decir un «viaje de ida y vuelta».

d) La devolución del capital en el contrato de préstamo dinerario llevaba aparejada la carga de intereses o réditos, que frecuentemente eran muy altos, hasta llegar al $25 \circ 30 \%$. No obstante el riesgo en los contratos de préstamo era importante a pesar de que contractualmente se garantizase con el propio navio, fundamentalmente por las dificultades de la navegación, el complicado arte de navegar, la construcción naval de la época, los peligros de piratas $u$ otras flotas, la posibilidad muy alta de fraude en algunos contratantes, etc., todo lo cual provocaba el frecuente incumplimiento de esos contratos. De ahí los frecuentes litigios observados en el derecho mercantil griego, y las frecuentes pérdidas del capital colocado en negocios de transporte marítimo.

e) El pago de intereses se contempla a lo largo del derecho griego en contratos similares al que nos ocupa. En el que estudiamos se dice en varias ocasiones: «...después de que hubiesen convenido los intereses..." (LVI, 5); «...entonces exigimos cobrar el préstamo y los intereses en un principio estipulados. Pero este sujeto nos trató tan insolentemente, que se negó a dar los intereses consignados en el contrato: Si queréis, dijo, cobrar la parte proporcional a la travesía realizada, os daré, añade, los intereses hasta Rodas, más no podría dar.» (LVI, 12); «...y no convenir en los intereses hasta Rodas...» (LVI, 14); «...亡por qué estás en desacuerdo respecto de los intereses, y pretendes que nosotros cobremos los réditos hasta Rodas?...» (LVI, 32). Y así varias veces más.

f) El contrato contempla, además de los intereses estipulados, para el caso de incumplimiento, una cláusula penal. La garantía es la propia nave (lo que nos indica ya que los arrendadores del transporte son, a la vez, propietarios del medio de transporte, es decir, la nave), según parece desprenderse de la demanda: «...recibió de nosotros en préstamo sobre la nave 3.000 dracmas con la condición de que el navío regresara a Atenas...».

Es decir, que el contrato contempla el transporte de una carga de trigo, haciendo una travesía desde Atenas a Egipto, cargarlo y de allí a Atenas de nuevo.

Si eso se incumple se pagará el doble del préstamo, es decir, 6.000 dracmas, más los intereses correspondientes: «...Este (el contrato) ¿qué dice y a dónde ordena hacer la travesía? De Atenas a Egipto y de 
Egipto a Atenas; si no, manda pagar doble dinero. Si has hecho eso, ninguna falta cometes, pero si no lo has hecho, ni has llevado la nave a Atenas, en justicia debes tú ser castigado con la pena suplementaria del contrato...”.

El núcleo contractual es la devolución solidaria del préstamo con intereses, y en su defecto, como dice el propio contrato: «si...no presentan las garantías públicamente (el propio navío) y libres de derechos de embargo, o ejecutan una acción en contra del contrato, paguen el doble de dinero».

De modo que, no devuelta la suma ni los intereses, la cláusula penal ordena la entrega del navío libre de cargas (libre de derechos de embargo) a los prestamistas.

Otra importante cuestión a contemplar es la excepción procesal, en los procedimientos civiles del derecho mercantil ático de los siglos $\mathrm{vi} / \mathrm{v}$, a.C. al objeto de despojar de contenido jurídico una acción reclamatoria, similar o diferente a que la hemos visto, y que podría realizarse a través de una

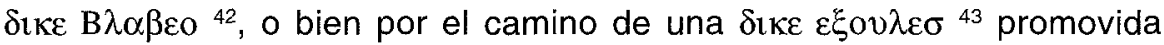
por el demandante que utilizando una $\delta$ เ $\varepsilon \varepsilon \mu \mu \varepsilon v o t$, se amparara en las

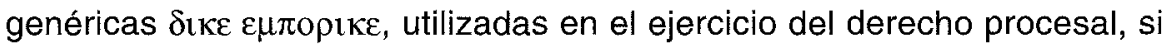
nos guiamos por las fuentes de la época ${ }^{44}$.

Tampoco debemos olvidar que en toda sociedad antigua se vislumbra primeramente un derecho penalizador, puesto que la noción que se tenía del delito era, en principio religiosa y proveniente de la impiedad de los hombres. De modo que la pena comenzó a imponerse con ánimo aplacatorio a los dioses agraviados por la conducta del infractor. De tal suerte

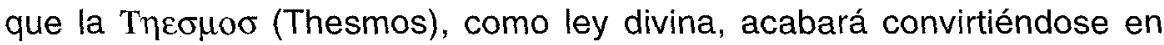
una ley humana y por tanto positiva. De ahí al concepto de responsabilidad (del "yo para con los otros que conviven conmigo") primero penal y luego civil, mercantil, etc., sólo habrá un paso ${ }^{45}$.

Sabemos que las leyes griegas, como antes las egipcias y más tarde las romanas, se grababan sobre estelas de piedra. Tal es el caso de las

\footnotetext{
Una acción judicial por daños y perjuicios.

Acción general de reclamación.

Demóstenes. «Contra Zenótemis» y «Contra Apaturio».

45 Alonso Y Royano, F.: Vid el presente texto a lo largo de su estructura. También un interesante trabajo (por el momento inédito, sobre la iconografía en el derecho penal).
} 
leyes de Dracón, que luego se publicaron nuevamente en el 409/408 a.C. ${ }^{46}$.

Tal legislación contemplaba un enjuiciamiento procesal muy completo . Así la suma litigiosa en que se cifraba el objeto de un proceso recibía el nombre de $E \pi \circ \beta \varepsilon \lambda \iota \alpha$ (epobelía) y respecto a las diversas acciones a emplear en los procedimientos judiciales destacaban la $\delta \mathrm{\imath} \varepsilon \varepsilon \alpha \pi \eta$ $\alpha \mu \varepsilon \sigma$ (diké

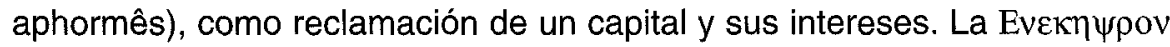
(Enékhyron) o representación genérica de una garantía real, y particularmente de una prenda, o los procedimientos donde se ventilaban cuantías indeterminadas, conocidos como $\delta \mathrm{i} \alpha \alpha \mathrm{l} \alpha \tau \imath \mu \varepsilon \tau o l$ (dikai atímêtoi).

El desarrollo jurídico en el derecho griego, y concretamente en el civil, donde se daba prevalencia a la autonomía de la voluntad, dentro de una regulación legal permisiva siempre que fuese lícita (contemplada en las leyes), llevaba a la necesidad de un procedimiento judicial, o derecho pro-

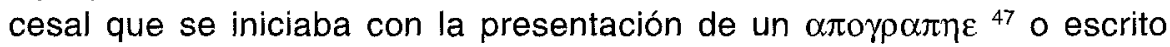
conteniendo una demanda al tribunal, previo el requisito de pago al erario público, el cual era trasladado al demandado para su conocimiento y contestación, si le convenía, mediante los $\kappa \lambda \varepsilon \tau \varepsilon \rho \varepsilon \sigma$ (klêtêres), cargo u oficio necesario para la presentación y citación a juicio.

En cuanto al órgano juzgador podía ser uni o pluripersonal, y estar compuesto por jueces o por árbitros. Éstos eran designados por sorteo entre ias 10 tribus griegas. $Y$ en cuanto a este tribunal arbitral privado, su laudo no era apelable ante los tribunales ordinarios, y la vista, ordinariamente, tenía lugar en terrenos tan sacros como la Helíea ${ }^{48}$, la Eneide o el Theseum, junto al Ágora.

46 Demóstenes en "Contra Evergetes y Mnesíbulo, por falsos testimonios». XLVII, 71.

Así se acredita también en "Contra Neera», cuando dice: "Y después de haber escrito esta ley en una estela de piedra, la colocaron en el templo de Dioniso, cabe el altar, en Limnas (y esta estela todavía hoy se levanta mostrando lo escrito en oscuras letras áticas "es decir, anteriores al año 403 a.C.").

Lo mismo puede decirse de la ley sobre la interdicción, atribuida a Dracón, y que fue renovada y grabada en piedra en el 409 a.C., y que no era otra cosa que una excomunión excluyente del interdicto de los lugares sagrados y del ágora.

47 Que realmente era cualquier escrito que describiese una situación creadora de derechos y obligaciones. Igualmente recibía ese nombre un simple inventario de bienes. Al fin y al cabo era un escrito donde se reflejaban determinadas obligaciones (las creadas por el propio inventario: bienes que a «alguien» pertenecen).

48 Que era un jurado popular compuesto de 6.000 ciudadanos atenienses (mayores de 30 años y elegidos por sorteo entre los que se encontraban en plenitud de sus derechos cívicos), si bien el oficio de juzgar se realizaba en la práctica por medio de una pequeña porción de ellos. 
Las partes, una vez presentado el apografé ante el tribunal, dado que el procedimiento era mixto, exponían oralmente su demanda, siguiendo el principio de inmediatez, con la aportación probatoria acompañada de los necesarios soportes documentales y testificales, a la vez que se admitía como prueba la tortura ${ }^{49}$.

La exposición oral de la demanda debía hacerse por las propias partes litigantes, excepto una situación de incapacidad, minoría de edad, esclavitud, sexo femenino, libertos o metecos, en cuyo caso debían ser representados por tutores, dueños o patronos. No obstante con permiso del tri-

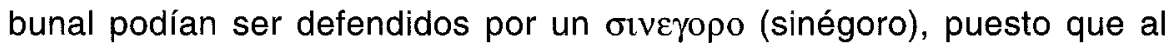

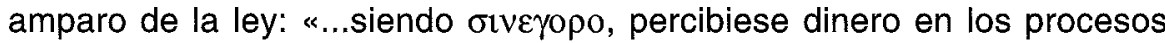
privados o públicos, sean las denuncias públicas de estos hechos ante los temóstetas». Es decir, que el sinégoro no era otra cosa que una especie de abogado defensor de oficio para los casos de incompetencia de la propia parte. Así pareció suceder a lo largo del siglo Iv a.C.

De todos modos en "Contra Neera» Teomnesto actor, acciona contra los demandados, la extranjera Neera y el político Estéfano, a través de una $\gamma \rho \alpha \pi \eta \varepsilon \xi \varepsilon v i \alpha \sigma$ (graphé xenías) iniciando la defensa ante el tribunal para, a continuación, ceder la palabra en calidad de sinégoro al autor del discurso que ha llegado hasta nosotros.

En el derecho procesal griego las partes tenían que deponer confesión como tales confesantes, pero no como testigos, al amparo de lo que una ley ateniense de la época expresa: "Es obligatorio para las partes responder a preguntas de la otra, pero no deponer testimonio».

Legalmente estaba prohibido el testimonio entre ausentes, o de

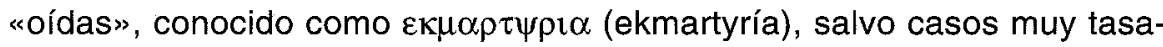
dos. Sin embargo hacía prueba la $\mu \alpha \rho \tau \psi \rho ı \alpha$ (martyría) o testimonio entre presentes. En efecto la ley decía: "Sea posible deponer testimonios de oídas de un muerto, y el testimonio escrito del de allende las fronteras, y del imposibilitado." Así lo expresa Apolodoro en el segundo discurso contra Estéfano.

El derecho griego admitía múltiples excepciones, entre las que podemos destacar por su uso, la ilegalidad, como proposición de una de las

49 Dice DEMósteNES en «Contra Timoteo» XLIX 55: «...le pregunté al árbitro si todavía era esclavo Escrión, y le exigí que en su piel diera la prueba». 
partes procesales respecto a una ley o decreto, aparentemente vigente en que pretendiera ampararse el demandado, impidiendo de ese modo su eficacia y utilidad procesal, y que prosperara la demanda, hasta en tanto se diese conclusión al procedimiento en curso por ese motivo.

Si bien es cierto que una excepción procesal a la demanda, impedía teóricamente entrar en el fondo del asunto, es lo cierto que las partes, o sus defensores ( $\sigma \psi v \varepsilon \gamma o \rho \circ \sigma)$, procuraban hacerlo, a veces incluso con la permisión y hasta el beneplácito de los jueces que, de este modo, tenían más elementos de juicio a la hora de emitir el correspondiente laudo o sentencia, si bien en cualquier momento del proceso podían impedir el uso de la palabra a los litigantes, incluso hasta el punto de producir una verdadera indefensión a las partes.

Respecto al soporte documental era introducido en urnas situadas frente al tribunal, y selladas de tal suerte que no había posibilidad de introducir nuevos y posteriores documentos.

Dentro del período probatorio no se contemplaba la pericial, pero determinados testimonios, como los procedentes de médicos, o libros de contabilidad bancaria, cual es el caso de banquero Pasión (s. IV a.C. debido a su reconocida honradez, se invocaban frecuentemente en los tribunales y arbitrajes, como modélicos, y así llegaron a tener, si no un valor legal, sí un valor moral, superior a otros y se consideraron una prueba cuasi pericial.

Es sabido que cada parte litigante disponía de un tiempo tasado para exponer sus alegaciones, tiempo que era medido por una clépsidra ${ }^{50}$. Sin embargo la lectura de los testimonios en el proceso no se computaba el tiempo concedido a cada parte.

Venía despues la sentencia o resolución judicial, tras el correspondiente sorteo entre los jueces sobre quién emitiría el parecer mayoritario, exactamente igual a como ahora se hace a través del ponente.

Lo dicho hasta aquí sirve a modo de acercamiento general a los procesos, a los que no eran ajenas las causas comerciales, y por tanto el co-

50 Reloj de agua que medía el tiempo que cada parte debía emplear en su exposición ante el tribunal. Dependiendo de la cuantía del litigio, el tiempo otorgado era mayor o menor. Así para una cuantía de 3.000 dracmas, correspondía al exponente un discurso de una duración de 7 «chus» de agua. 
mercio maritimo (cuyos procesos cabía llevar a sede arbitral privada, pero no a procedimientos públicos) que en realidad era el comercio más importante de Grecia.

Aún así no estamos en condiciones de disponer de un conocimiento sino sólo aproximado del derecho mercantil griego, de suerte que conociendo algunas instituciones jurídicas, como las correpondientes a los «intendentes de los arsenales", que relacionados con el concejo vigilaban la construcción de buques, otras las desconocemos por completo.

De modo que ya hemos visto que los procedimientos reclamatorios de derecho marítimo habían de seguirse ante un órgano colegiado compuesto por 6 arcontes, que recibía el nombre de tesmótetas y que uno de los negocios más frecuentes del tráfico marítimo era el transporte de trigo, dada la penuria de ese cereal en Atenas durante el siglo IV a.C., bien a través de naves propias o de transporte arrendadas por los comerciantes, desde los puntos exportadores como Masalia (Marsella), Sicilia y Egipto, hasta Atenas, como emporio importador, para desde alli exportar a su vez otro tipo de mercaderías, entre las que figuraba el vino y el aceite. Las rutas comerciales marítimas más frecuentadas eran las citadas y las procedentes del Bósforo por el Ponto.

Naturalmente esos negocios daban lugar a las más diversas situaciones reclamatorias y su tratamiento a través de distintas instituciones jurídicas de derecho mercantil. Tal es el caso del préstamo marítimo o préstamo a la gruesa, que más tarde los romanos llamarán «fenus nauticum»; o la $\pi \rho \alpha \sigma \imath \sigma \varepsilon \pi \imath \lambda \psi \sigma \varepsilon \imath$ (prâsis epí Lýsei), es decir la venta con derecho de retención, o pacto de retroventa, que para los romanos habría de ser luego un "madatum pecuniae crecendae», o la subrogación de un tercero en los derechos del acreedor; o el $\alpha \mu \pi \eta$ ๆ $\tau \varepsilon \rho \pi \lambda$ ovo (amphoteróplous) o contrato especial de préstamo para una travesía «de ida y vuelta» (que éste sería el pleito del que nos hemos venido ocupando); o figuras como la de la solidaridad contractual activa y pasiva, el arbitraje marítimo, o la de los síndicos como un órgano de gestión y administración de la quiebra, serían algunas de las instituciones del viejo derecho griego.

Así que en el campo de las excepciones contempladas en el derecho procesal griego, éstas eran la defensa otorgada al demandado contra una demanda de objeto inexistente, injusta o caduca, con pretensión de hacerla ineficaz, exponiendo las causas por las que devenía la ineficacia. Así lo dice el discursante forense en "Contra Apaturio", en época de Alejandro, por alguien que no parece haber sido Demóstenes. Veamos: 
«...Por otra parte, a quienes se ven sometidos a juicio por obligaciones que no existieron, la ley les concede que busquen refugio en la excepción, con objeto de que nadie sea víctima de una demanda calumniosa, sino que las acciones estén a favor de los comerciantes y navieros verdaderamente lesionados. $Y$ ya muchos demandados en procesos mercantiles, mediante la interposición de excepciones a tenor de la citada ley y su comparecencia ante vosotros, convencieron a quienes sostenían la causa en su contra de estar acusado sin derecho, y presentar demanda falsa so pretexto de ejercer el comercio».

De modo que la excepción procesal en el campo del derecho marítimo ático podía esgrimirse en principio en los procesos en que eran parte comerciantes y navieros. No obstante en procesos diferentes a los del derecho mercantil también se excepciona. Tal es el caso de Formión ${ }^{51}$ o el de Panténeto ${ }^{52}$ entre otros, lo que nos lleva a la conclusión de que además de lo dicho también se contemplaba en aquellas reclamaciones efectuadas sobre minería, fabricación de armas y escudos, etc. Parece pues que los requisitos para excepcionar eran:

a) Ser parte demandada.

b) Asuntos pertenecientes al derecho mercantil (derecho marítimo, minería, fabricación diversa, comerciantes y derecho bancario).

$Y$ las causas de excepción:

1. Inexistencia de la obligación.

2. Pago o cumplimiento de la obligación.

3. Prescripción por el transcurso de 5 años.

51 «Excepción en favor de Formión» XXXVI, 2. Discurso auténtico de Demóstenes, hacia el

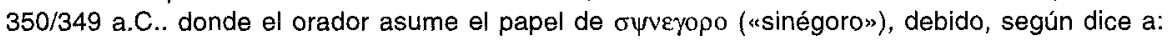
"La falta de experiencia en la oratoria y cuán incapaz es Formión".

52 Otro de los discursos auténticos de Demóstenes, fechado en el 346/345 a C. y cuya excepción la suscita una demanda por una venta con pacto de retroventa o derecho de redención sobre un taller minero, y sus obreros esclavos. 